Research Article

\title{
Prevalence and Phylogenetic Diversity of Pathogenic Fusarium Species in Genotypes of Wheat Seeds in Three Rift Valley Regions, Kenya
}

\author{
Otieno P. Kheseli $\mathbb{D D}^{1},{ }^{1}$ Imbahale S. Susan $\mathbb{D}^{1},{ }^{1}$ Okoth Sheila $\left(\mathbb{D},{ }^{2}\right.$ Miriam Otipa, ${ }^{3}$ \\ and Wekesa V. Wafula $\left(^{4}\right)^{4}$ \\ ${ }^{1}$ Department of Applied and Technical Biology, Technical University of Kenya, P.O Box 52428-00200, Nairobi, Kenya \\ ${ }^{2}$ School of Biological Sciences, University of Nairobi, P.O Box 30197-00100, Nairobi, Kenya \\ ${ }^{3}$ Kenya Agricultural Research and Livestock Organization, Kabete, P.O Box 14733-00800, Nairobi, Kenya \\ ${ }^{4}$ Flamingo Horticulture (K) Limited (Dudutech), P.O BOX 1927-20117, Naivasha, Kenya
}

Correspondence should be addressed to Otieno P. Kheseli; phanicekheseli@yahoo.com

Received 9 July 2020; Revised 23 December 2020; Accepted 8 January 2021; Published 30 January 2021

Academic Editor: Jiban Shrestha

Copyright (c) 2021 Otieno P. Kheseli et al. This is an open access article distributed under the Creative Commons Attribution License, which permits unrestricted use, distribution, and reproduction in any medium, provided the original work is properly cited.

\begin{abstract}
Wheat is a source of nutrients for around $40 \%$ world's population and the second most important cereal crop in Kenya. However, Fusarium head blight (FHB) hinders sustainable sufficient production of the crop, causing both economic and health losses. With the emerging unfavorable climatic changes, effective disease management strategies and adequate seed system are necessary to meet the deficiency. Current information on prevalence of the causative pathogens in varieties of wheat genotypes is a critical prerequisite to such strategies. This study aimed at determining the prevalence of pathogenic Fusarium species in seeds of developed varieties of wheat genotypes in three major wheat-producing regions in Kenya. A total of 260 samples of 18 wheat genotypes from 123 farms were collected. Peptone pentachloronitrobenze agar was used for fungal isolation, while identification of Fusarium spp. was based on the gene encoding translation elongation factor 1- $\alpha$ (tef1-alpha) sequence analysis. Fusarium spp. isolated include Fusarium poae, F. tricinctum, F. heterosporum, F. culmorum, F. equiseti, Fusarium sp., F. verticillioides, and F. oxysporum. There was no significant difference in prevalence of Fusarium spp. pathogens among the three regions studied. Fusarium spp. diversity index for Nakuru was 2.008, Narok was 1.4603, and Uasin Gishu was 1.2337. Wheat produce from farmsaved seeds yielded $66.25 \%$ of the isolates, while the produce from certified commercial wheat seeds yielded $33.75 \%$ of the isolates. The significant finding of the study is that Fusarium spp. associated with mycotoxins that contaminate the wheat food chain seem to be flourishing in all the sampled wheat seed genotypes from the regions studied. Information on the prevalence and diversity of the pathogens on persistence of the disease in the crop is critical in advancing integrative FHB control measures.
\end{abstract}

\section{Introduction}

Fusarium spp. is one of the most significant filamentous pathogenic fungal genera that is ubiquitous around the globe. They are field or soil fungi, causing wilts, seedling blights, rots, and cankers in susceptible plants [1]. Fusarium spp. contamination is a major agricultural problem that reduces the quality and yield of agricultural products while producing mycotoxins that have virulence factors responsible for many diseases in humans and farm animals [2].
Wheat (Triticum aestivum) is a staple source of nutrients for approximately $40 \%$ of the world's population and is the most widely grown crop in the world, cultivated on more than 218 million ha. In addition, its world trade is greater than all other crops combined [3, 4]. However, infestation of fungal pathogens in the crop is a serious worldwide problem due to various factors. Unfavorable climatic conditions and agronomy-related issues have been reported to be critical in this respect [5-8]. Pathogenic Fusarium spp. is the main cause of Fusarium head blight (FHB) that causes devastating 
wheat grain destruction with resultant accumulation of mycotoxins.

Globally, various control measures are under investigation by researchers with the aim of effectively protecting the crop from FHB. This has involved the use of different pre-harvest and post-harvest methods, starting from agrotechnical methods that limit the source of primary infection. Post-harvest control measures include physical methods such as proper harvesting that does not damage the grains, crop rotation tillage, fertilization, use of appropriate quality seed material and the timely sowing period $[9,10]$, education and training of agricultural producers in application of good agricultural practices. Although fungicide efficacy against FHB has been inconsistent due to the short time framework for application as well as limited number of available fungicides [10], their role in control of FHB cannot be ignored among pre-harvest control measures. Chemical control of FHB in wheat influences the disease intensity in spikes and deoxynivalenol contamination in grains [11]. Timely use of the correct dosage of the effective type of fungicides [12-14] has been reported to be an applicable FHB control measure especially during plant flowering. Also included in this category is the use of resistance inducers including biopreparations based on antagonistic microbial agents, endophytes and other biologically active ingredients, and nonchemical fungicides and plowing [15-18]. Selection and use of cultivars with a high level of resistance to Fusarium spp. infestation [10, 17] and to lodging [19] cannot be overemphasized. Use of a combination of preharvest measures when conditions are favorable for Fusarium spp. infestation is more effective $[9,20]$ since they limit the survival of the pathogens in debris, reducing their presence in field and infestation severity. However, the ever-changing farm and climatic conditions require application of consistent effective FHB control measures such as the use of wheat genotypes that are highly resistant to Fusarium spp. pathogens. The current study investigated the prevalence and diversity of pathogenic Fusarium spp. in varieties of wheat genotypes from three major wheat-producing regions in the Kenyan Rift Valley in line with factors determining selection of the cultivated genotypes.

1.1. Background of the Study. Wheat is Kenya's second most important cereal crop after maize and an economically important crop among the large and small-scale farmers [21]. It is grown in areas above 1500 metres above sea level, in southern and upper Rift Valley regions (Nakuru, Narok, and Uasin Gishu) and in the eastern part of Kenya (Nanyuki and Meru). Wheat production is carried out by small, medium and large-scale farmers and the industry, supported by about 20 millers, contributes $1.4 \%$ and $30 \%$ to overall and cereal GDP [22], respectively. The high costs of farm inputs and land fragmentation among other factors have led to a shift in production from large-scale and medium-scale commercial farms using capital-intensive technology to production mostly by small-scale farmers [23].

Wheat requires a fine planting bed for uniform germination. In this view, farmers are encouraged to have the land thoroughly ploughed and harrowed, free from growing weeds and weed seeds, at least 4 weeks before planting to ensure that the land does not have fresh compost (plant material that is not fully rotten) during planting. Fertilizer application is recommended during planting depending on the soil type as per the soil analysis report. During planting, diammonium phosphate (DAP) at $200-250 \mathrm{~kg} \mathrm{Ha}^{-1}$ is recommended as determined by factors such as the stage of the crop, since availability of nitrogen is important during tilling, stem extension, and ear emergence.

Diseases, pre-harvest, and post-harvest losses are the major recurring challenges hindering optimal production of wheat. Occurrence of wheat devastating fungal diseases such as wheat rust [24] and FHB [25-27] has been reported as the major setback to wheat production in Kenya. Generally, other than good farm management practices, the main wheat crop protection regime used by farmers in Kenya against all fungal foliar wheat diseases such as wheat rust is the use of fungicides. Foliar diseases can increase the susceptibility of wheat spikes to FHB. Consequently, fungicides become crucial in reducing the effects of the diseases on wheat. However, the low efficacy and limited spectrum of such fungicides create a gap in control of resistant fungal diseases such as FHB. Although disease resistance or tolerance remains a driving goal of Kenya Agricultural and Livestock Organization's (KALRO') wheat research program, it remains a challenge for the recommended wheat varieties [21]. Hence, there is consistent development of wheat genotypes with high stable yields, tolerance to biotic and abiotic stresses, pre-harvest sprouting diseases, and insect pests, so that farmers from different growing regions in the country can select the most suited variety [21]. Therefore, current information on prevalence and diversity of Fusarium spp. in the existing and cultivated wheat genotypes is important prerequisite information in integrated management of FHB and the improvement or development of other genotypes with better disease resistant qualities. The current study evaluated the occurrence and diversity of pathogenic Fusarium spp. in the developed wheat genotypes in three major wheat-producing regions within the Kenyan Rift Valley and the factors considered by farmers in selecting the cultivated wheat varieties.

\section{Materials and Methods}

2.1. Study Area. The study was carried out in three regions situated within the Kenyan Rift Valley, the main commercial wheat-growing zone. Figure 1 shows the location of each site generated using the geographical positioning system (GPS). The average rainfall range was between $20 \mathrm{~mm}-40 \mathrm{~mm}$ in Narok, $60 \mathrm{~mm}-80 \mathrm{~mm}$ in Uasin Gishu, and $40 \mathrm{~mm}-60 \mathrm{~mm}$ in Nakuru; whereas, the average temperature range in Narok was $18^{\circ} \mathrm{C}-22^{\circ} \mathrm{C}$, in Usain Gishu $<18^{\circ} \mathrm{C}$, and $18^{\circ} \mathrm{C}-22^{\circ} \mathrm{C}$ in Nakuru during the study period. These areas have annual rainfall varying between $800 \mathrm{~mm}$ and $2000 \mathrm{~mm}$, with the amounts occasionally rising up to $2,500 \mathrm{~mm}$ in higher altitudes. Research on smallholder wheat technologies is performed by the National Plant Breeding Station based in Nakuru. The commonly cultivated crops on large-scale 


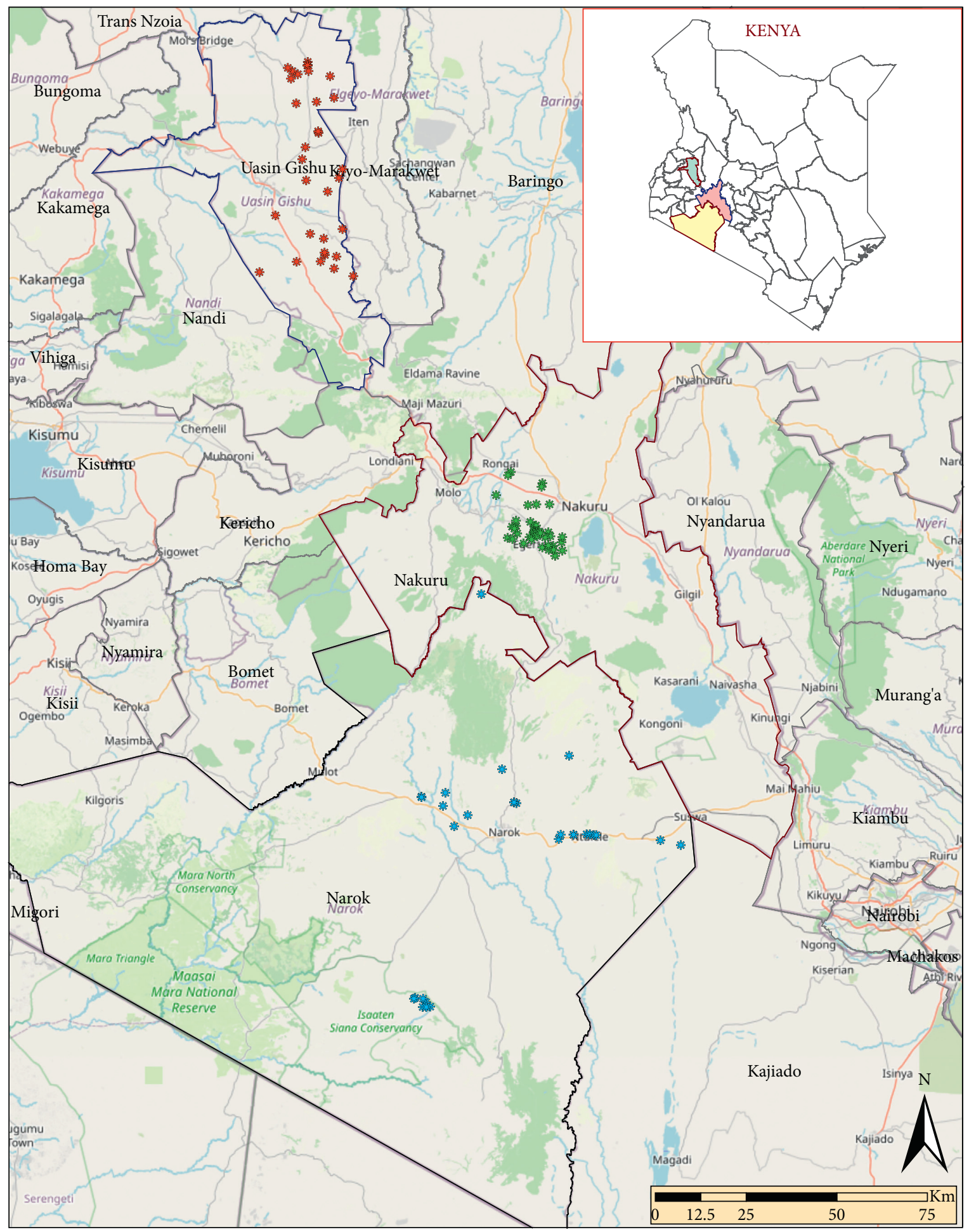

Key

* Uasin Gishu GPS coordinates

* Nakuru GPS coordinates

* Narok GPS coordinates

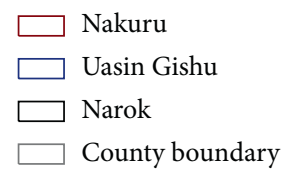

FIGURE 1: The location of each sampling site generated using the geographical positioning system (GPS). 
farms in the study regions are wheat, barley, and maize. Other subsistence crops such as legumes (beans), cabbages, kales, and Irish potatoes are also cultivated on small-scale basis. Farms barely stay fallow for 1-2 years before cultivation.

2.2. Field Sampling of Wheat Seeds. The sampling took place between September 2016 and October 2017 as follows: Narok, July $28^{\text {th }}$ to early September, 2016; Uasin Gishu region, November 8, 2016 to early December, 2016, Nakuru region: Nakuru-Naivasha area, February, 2017; and NakuruNjoro area, October, 2017. In Nakuru region, most of the sampling was carried out in Njoro, the main wheat-producing and research centre. Cross-sectional purposeful sampling was followed, whereby farms were randomly selected depending on the day of harvesting. Laboratory and file samples were taken from bulks of freshly harvested wheat grains using spear sampling technique $[28,29]$. The number of samples collected per farm varied as determined by farm size and ranged from 3 to 21 samples per site. Each wheat variety was sampled in replicates of three per sampling site and every sample weighed approximately 500 gm. Samples were packed in khaki papers and labelled and transported in cooler boxes to the laboratory, where they were stored at $4^{\circ} \mathrm{C}$ for isolation of Fusarium species. The sampling process included gathering information from wheat farmers on the genotypes of wheat seeds cultivated and criteria used in selection of the wheat genotypes, the use of farm-saved and certified commercial wheat seeds and last, common fungal diseases observed on the crop in the fields.

2.3. Preparation of Wheat Samples for Isolation and Characterization of Fusarium spp. To obtain representative samples from multiple samples procedures described by the authors of $[28,29]$ were used but with slight modifications. Multiple samples from specific farms and sites were aseptically poured into a sterile container (polythene paper bag) and manually mixed to make one homogenous composite sample. The composite sample was then manually reduced into portions of $500 \mathrm{gm}$ and labelled and randomly selected for use as test and file samples. Samples that weighed $500 \mathrm{gm}$ from collection sites were used directly as test samples after mixing. The methods developed by the authors of $[30,31]$ were adopted for use in the process of isolation and morphological characterization of Fusarium species. Approximately one hundred and fifty seeds of each test sample were randomly picked and soaked in $2 \%$ of $\mathrm{NaOCl}$ for 2 minutes. The seeds were then rinsed three times, each time in fresh sterile distilled water and dried on sterile muslin cloth in a laminar flow. Ten sterile seeds from each of the three replicates of every sample were randomly picked and plated in triplicates on selective media, peptone pentachloronitrobenze agar, and incubated at $25^{\circ} \mathrm{C}$ for $4-7$ days. These constituted 90 plated seeds for each sample. Germinating fungal colonies were subcultured on tap water agar at $25^{\circ} \mathrm{C}$ for a period of 7-14 days for sporulation. Spores of each isolate were examined using a microscope to ascertain distinctive characteristic features unique to Fusarium species. To obtain pure colonies, spores of each Fusarium spp. isolate were subjected to $10^{-4}$ fold serial dilution and cultured on water agar at $25^{\circ} \mathrm{C}$ for 18 hours. Hyphal tips of each fungal colony formed were subcultured in triplicates on three different media: potato dextrose agar (PDA), synthetic agar (SNA), and carnation leaf agar (CLA) under two different temperatures, $25^{\circ} \mathrm{C}$ and $30^{\circ} \mathrm{C}$, with alternating 12 hours of darkness and 12 hours of fluorescent light. This was carried out for further morphological characterization following procedures by the authors of $[32,33]$. Pure Fusarium spp. isolates were then stored as spore suspensions in $15 \%$ glycerol at $-80^{\circ} \mathrm{C}$ in Kenya Agricultural and Livestock Research Organization (KALRO) biotechnology laboratory for molecular characterization.

\subsection{Molecular Characterization of Fusarium spp}

2.4.1. DNA Extraction. Spores of each isolate were cultured on PDA at $25^{\circ} \mathrm{C}$ and alternating 12 hours of fluorescent light and darkness. DNA of each isolate was extracted between day 7 and day 14 depending on the quantity of mycelia using a Zymo Research Fungal/Bacterial DNA Mini Prep Kit (Epigenetics, Hatfield, South Africa) and according to the manufacturer's instructions. For optimal performance, betamercaptoethanol (user supplied) was added to the genomic lysis buffer to a final dilution of $0.5 \%(\mathrm{v} / \mathrm{v})$, i.e., $500 \mu \mathrm{l}$ per $100 \mathrm{ml}$. In the first step, approximately $10 \mathrm{mg}-20 \mathrm{mg}$ (wet weight) of fungal cells that had been resuspended in up to $200 \mu \mathrm{l}$ of isotonic buffer (e.g., PBS) were added to a ZR BashingBead $^{\mathrm{TM}}$ lysis tube $(0.1 \mathrm{~mm}$ and $0.5 \mathrm{~mm})$, and $750 \mu \mathrm{l}$ BashingBead $^{\mathrm{TM}}$ buffer was added to the tube before capping tightly. The preparation was then secured in a bead beater fitted with a $2 \mathrm{ml}$ tube holder assembly and processed at a maximum speed of $\geq 5$ minutes. Processing time varied based on sample input. The ZR BashingBead ${ }^{\mathrm{TM}}$ lysis tube $(0.1 \mathrm{~mm}$ and $0.5 \mathrm{~mm})$ was then centrifuged in a microcentrifuge at $10,000 \mathrm{xg}$ for 1 minute. Up to $400 \mu \mathrm{l}$ of the supernatant was transferred to the Zymo-Spin ${ }^{\text {тм }}$ III-F filter in a collection tube and centrifuged at $8,000 \mathrm{xg}$ for 1 minute, and the Zymo-Spin ${ }^{\mathrm{TM}}$ III-F filter was discarded. Next, 1,200 $\mu \mathrm{l}$ of genomic lysis buffer was then added to the filtrate in the collection tube and mixed well. $800 \mu \mathrm{l}$ of the mixture was added to a Zymo-Spin ${ }^{\mathrm{TM}}$ IC column 2 in a collection tube and centrifuged at 10,000 x g for 1 minute. The flow through from the collection tube was discarded, and the previous step (step 6) was repeated. $200 \mu \mathrm{l}$ DNA pre-wash buffer was then added to the Zymo-Spin ${ }^{\mathrm{TM}}$ IC column in a new collection tube and centrifuged at 10,000 $\mathrm{xg}$ for 1 minute. $500 \mu \mathrm{l} \cdot \mathrm{g}^{-1}$ DNA Wash Buffer was added to the Zymo-Spin ${ }^{\mathrm{TM}} \mathrm{IC}$ column and centrifuged at 10,000 xg for 1 minute. The Zymo-Spin ${ }^{\mathrm{TM}}$ IC column was then transferred to a clean $1.5 \mathrm{ml}$ microcentrifuge tube, and $20 \mu \mathrm{l}$ (10 $\mu \mathrm{l}$ minimum) of DNA elution buffer was added directly to the column matrix and incubated for 1 minute. This was followed by centrifugation at $10,000 \mathrm{xg}$ for 30 seconds to elute the DNA, using a Zymo Research Fungal/ Bacterial DNA Mini Prep Kit (Epigenetics, Hatfield, South Africa) and according to the manufacturer's instructions. 
2.4.2. Polymerase Chain Reaction (PCR) Amplification of Fusarium spp. DNA. A set of primers targeting the gene encoding translation elongation factor $1-\alpha$ (tef1- $\alpha$ )- Ef1 (forward primer: 5'-ATGGGTAAGGA (A/G) GACAAGAC-3') and EF2 (reverse primer: 5'-GGA (G/A) GTACCAGT (G/C) ATCATGTT-3') was used to amplify $700 \mathrm{bp}$ fragment [34]. The PCR was performed in $25 \mu \mathrm{l}$ reactions which included $1 \mu \mathrm{l}$ of a $1: 10$ or $1: 100$ DNA dilution, $1 \mathrm{U}$ RedTaq DNA polymerase (Sigma-Aldrich Company, Milan, Italy), $2 \mu \mathrm{l}$ RedTaq buffer supplemented with $1.7 \mu \mathrm{l}$ of $22 \mathrm{mM}$ $\mathrm{MgCl}_{2}$ for a final concentration of $3.0 \mathrm{mM}, 10 \mathrm{mM}$ deoxyribonucleotide) and $1.0 \mu \mathrm{M}$ of each primer: reverse and forward (ef1 and ef2). Reactions were run in a Mastercycler ep-gradient (BioRad, California, USA) with a thermal profile of $4 \mathrm{~min}$ at $94^{\circ} \mathrm{C}$ followed by 35 cycles of $60 \mathrm{~s}$ at $94^{\circ} \mathrm{C}, 60 \mathrm{~s}$ at $57^{\circ} \mathrm{C}$ and $1 \mathrm{~min}$ at $72^{\circ} \mathrm{C}$ followed by $72^{\circ} \mathrm{C}$ for $5 \mathrm{~min}$. The amplified DNA was electrophoresed in 1.5\% (w/v) Trisacetate ethylene diamine tetraacetic acid (EDTA) agarose gels. Amplicons were visualized at $700 \mathrm{bp}-710 \mathrm{bp}$ using a $1 \mathrm{~kb}$ bp DNA ladder (Bioline) as a size standard. A concentration of $1 \%$ agarose gel was used. To make the gel, the agarose was boiled at $100^{\circ} \mathrm{C}$ for 5 minutes in a conical flask and left to cool to $55^{\circ} \mathrm{C}$. Then, $0.3 \mu \mathrm{l}$ of ethidium bromide was added while swirling the flask to enable the gel mix with ethidium bromide. The mixture was poured into a gel tank with the combs on and left to solidify. Molecular marker $(2 \mu \mathrm{l})$ was added to one well, and DNA $(4 \mu \mathrm{l})$ plus the loading dye was added to other wells and the arrangement was noted. Distilled water was used as a control. The gel was run for 45 minutes at $80 \mathrm{~V}$ and viewed under Geldoc (BioRad, Molecular Imager Gel Doc XR-CLASS, Imaging System, California and USA). A qPCR to estimate the severity of infection for each given Fusarium spp. per sample was not performed since our interest for DNA analysis was to ascertain the species identity of the isolates.

2.4.3. Nucleotide Sequencing and Analysis of tef1- $\alpha$ Nucleotide Sequences. Amplification products of TEF-1 gene were purified using a QIAquick Gel Extraction Kit according to manufacturer's instructions (Qiagen manual). Sequencing of both strands was performed in the ABI 3700 DNA Sequencer in the Sequencing Service Unit of Macrogen (Netherlands). The ef1- $\alpha$ (tef1- $\alpha$ ) raw nucleotide sequences were assembled, contigs generated, and consensus sequences retrieved using Geneious version 11.1.5 software. Basic Alignment Search Tool for Nucleotide Sequences (BLASTN), https://blast.ncbi.nlm.nih.gov/Blast.cgito, was used in retrieving sequences with high similarity index with those from National Centre for Biotechnology Informatics (NCBI) database. The retrieved sequences were aligned together with the consensus sequences of the isolates using ClustalW, a matrix-based algorithm build in Geneious version 11.1.5 software. A phylogenetic tree was generated to infer relatedness of the aligned 49 sequences. Maximum likelihood (ML) analysis was performed and a phylogenetic tree (Figure 2) was built through the Tamura-Nei model. One thousand bootstrap replicates were performed for assurance of stability and robustness of each of the branch
$[35,36]$. The tree with the highest log likelihood $(-31270.16)$ was shown. The percentage of trees in which the associated taxa clustered together was shown next to the branches. Initial trees for the heuristic search were obtained automatically by applying Neighbor-Join and BioNJ algorithms to a matrix of pairwise distances estimated using the maximum composite likelihood (MCL) approach and then selecting the topology with the superior log likelihood value. There were 4167 positions in the final dataset. Evolutionary analysis was conducted in MEGA X [35].

\subsection{Data Analysis on Prevalence and Diversity of Fusarium} $s p p$. Data was analyzed in SPSS using one-way ANOVA to compare prevalence of each of the Fusarium spp. isolated. The analysis was done with respect to overall occurrence and types of Fusarium spp. in each of the sampled wheat genotypes among the three regions, at 0.05 significance level. Fusarium spp. with significantly different means among the regions were subjected to further analysis using the LSD test for multiple comparisons to identify any differences in overall occurrences between any two regions. To determine species richness and their relative abundance in each region, diversity indices were computed using Simpson's and Shannon's diversity equations. Evaluation of the prevalence of Fusarium spp. between wheat seeds arising from farmsaved seeds and certified commercial seeds was also performed using descriptive statistics.

Simpson's diversity index $(D)$ is given by

$$
D=1-\sum\left(p_{i}\right)^{2} .
$$

While Shannon's Weiner diversity index $(\mathrm{H})$ is given by

$$
H=-\sum p_{i} \ln p_{i},
$$

where "D" stands for Simpson's diversity index, "H" stands for Shannon's diversity index, " $\sum$ " is the sum of and " $p_{i}$ " is the relative abundance of each species, and "ln" is the natural logarithm.

\section{Results}

3.1. Wheat Genotype Preference by Farmers in the Rift Valley. Two hundred and sixty (260) samples of different genotypes of wheat seeds (Table 1) were collected from 123 wheat farms. Eighteen wheat seed genotypes were classified out of the 260 samples of wheat seeds collected. Sixty-six percent (66.25\%) was the produce of certified commercial wheat seeds and $33.75 \%$ was the produce of farm-saved wheat seeds (Table 2). Agro-economic factors that determined farmers' choice of wheat seed genotype to cultivate varied from potential weight of wheat yield, resistance of wheat grains to pests in storage, affordability of wheat seed genotype, resistance of wheat genotype to wheat rust, availability of the seeds of genotypes released in the market and free wheat seed genotypes offered for research purposes or for production of certified wheat seeds. Only $1.6 \%$ of the farmers whose wheat seeds were sampled cited FHB as a serious problem that affects the crop. However, the disease effects 


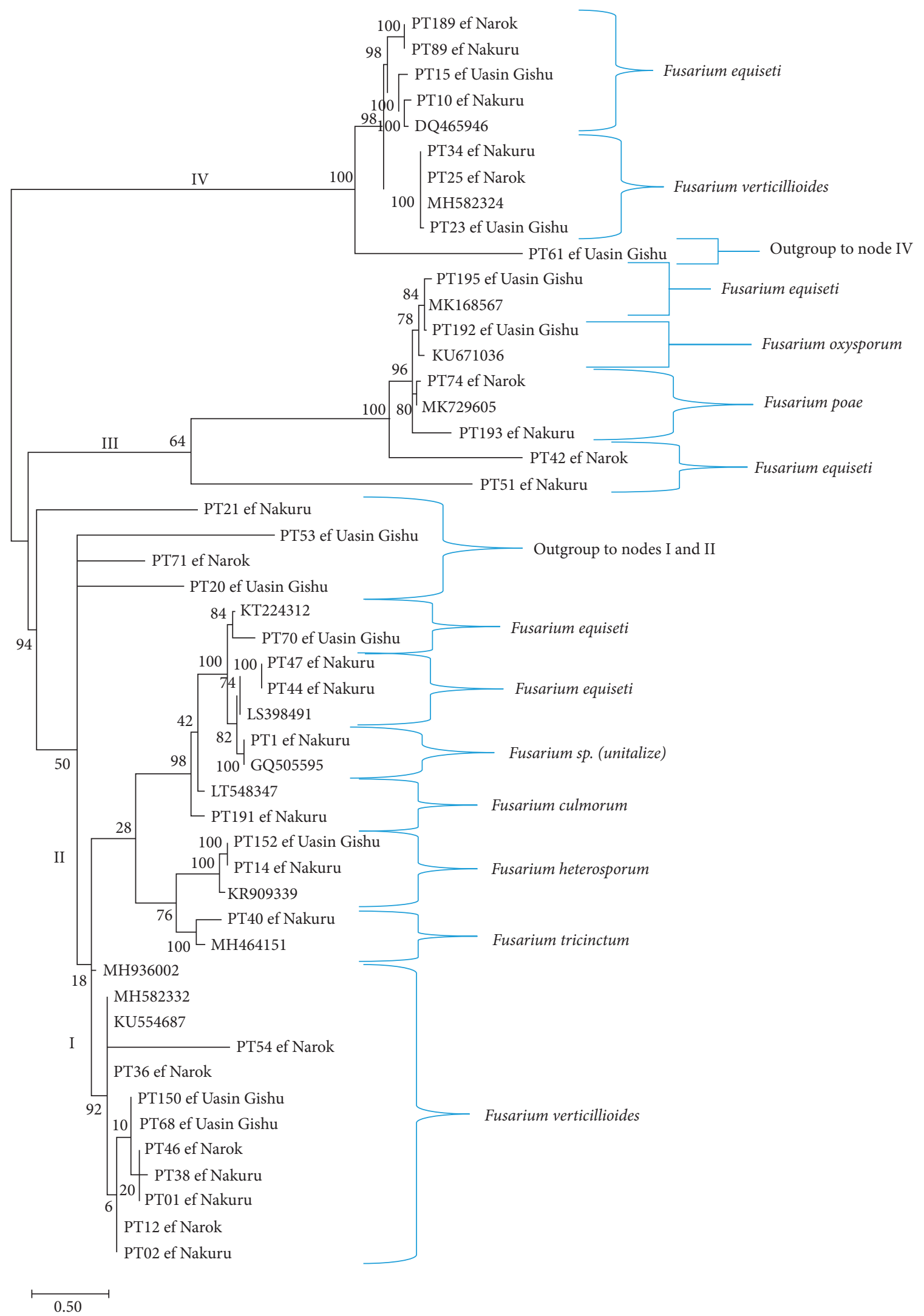

FIgURe 2: Phylogenetic tree of Fusarium spp. isolated from freshly harvested genotypes of wheat seeds in three Rift Valley regions, Kenya. The analysis was based on tef1- $\alpha$ gene sequences and by the maximum likelihood method with 1,000 bootstraps. 
TABLe 1: Wheat genotypes sampled in three Rift Valley regions, Kenya.

\begin{tabular}{|c|c|c|c|c|}
\hline \multirow{2}{*}{ Wheat genotype } & \multicolumn{3}{|c|}{ Region of sampling and no. of samples } & \multirow{2}{*}{ Total no. of samples } \\
\hline & Narok & Uasin Gishu & Nakuru & \\
\hline 1. Robin & 15 & 9 & 9 & 36 \\
\hline 2. Eagle 10 & 9 & 3 & 6 & 18 \\
\hline 3. Ibis & 3 & 0 & 3 & 6 \\
\hline 4. Njoro II & 30 & 82 & 15 & 127 \\
\hline 5. Korongo & 6 & 0 & 3 & 9 \\
\hline 6. Farasi & 3 & 0 & 0 & 3 \\
\hline 7. Mwamba & 6 & 0 & 3 & 9 \\
\hline 8. Hawk & 3 & 0 & 3 & 6 \\
\hline 9. Ruiru & 6 & 0 & 0 & 6 \\
\hline 10. Simba & 0 & 3 & 0 & 3 \\
\hline 11. Ngamia & 0 & 0 & 3 & 3 \\
\hline 12. Duma & 0 & 0 & 3 & 3 \\
\hline 13. Kingbird & 0 & 0 & 3 & 3 \\
\hline 14. K. Tai & 0 & 0 & 3 & 3 \\
\hline 15. Yombi & 0 & 0 & 3 & 3 \\
\hline 16. K. Wren & 0 & 0 & 3 & 3 \\
\hline 17. Kwale & 0 & 0 & 3 & 3 \\
\hline 18. K. Sunbird & 0 & 0 & 3 & 3 \\
\hline 19. Undisclosed & 8 & 4 & 4 & 16 \\
\hline Total & 89 & 101 & 70 & 260 \\
\hline
\end{tabular}

TABle 2: Produce of certified and farm-saved genotypes of wheat seeds and overall occurrence of Fusarium spp.

\begin{tabular}{|c|c|c|c|c|c|c|c|c|c|}
\hline \multirow[t]{2}{*}{$\mathrm{S} / \mathrm{N}$} & \multirow[t]{2}{*}{ Wheat genotype } & \multicolumn{6}{|c|}{$\begin{array}{c}\text { Occurrence of certified } \\
\text { and farm-saved wheat seed } \\
\text { produce }\end{array}$} & \multicolumn{2}{|c|}{$\begin{array}{c}\text { Percentage } \\
(\%) \\
\text { occurrence } \\
\text { of Fusarium } \\
\text { spp. }\end{array}$} \\
\hline & & $\mathrm{CT}$ & FS & $\mathrm{CT}$ & FS & $\mathrm{CT}$ & FS & $\mathrm{CT}$ & FS \\
\hline 1 & Njoro II & + & + & + & + & + & + & 2.5 & 25 \\
\hline 2 & Unidentified & - & + & - & + & - & + & - & 6.25 \\
\hline 3 & Eagle 10 & + & - & - & + & + & - & 3.75 & 7.5 \\
\hline 4 & Robin & + & - & - & + & + & - & 1.25 & 5 \\
\hline 5 & Mwamba & - & - & + & - & - & - & 2.5 & - \\
\hline 6 & K. Korongo & + & - & - & - & - & - & - & 6.25 \\
\hline 7 & Ruiru & - & - & - & + & - & - & - & 5 \\
\hline 8 & Hawk & - & - & - & + & - & - & 1.25 & 3.75 \\
\hline 9 & K. Ibis & - & + & - & + & - & - & - & 6.25 \\
\hline 10 & Duma & + & - & - & - & - & - & 5 & - \\
\hline 11 & Kwale & + & - & - & + & - & - & 3.75 & - \\
\hline 12 & Fahari & - & - & + & - & - & - & 2.5 & 2.5 \\
\hline 13 & Kingbird & + & - & - & - & - & - & 1.25 & - \\
\hline 14 & K. Tai & + & - & - & - & - & - & 1.25 & - \\
\hline 15 & Yombi & + & - & - & - & - & - & 2.5 & - \\
\hline 16 & K. Wren & + & - & - & - & - & - & 0 & - \\
\hline 17 & Simba & + & - & - & - & + & - & 2.5 & - \\
\hline 18 & Sunbird & + & - & - & - & - & - & 1.25 & - \\
\hline 19 & Ngamia & + & - & - & - & - & - & 2.5 & - \\
\hline & all \% occurrence o & of Fus & & $m \mathrm{sp}$ & & & & 33.75 & 66.25 \\
\hline
\end{tabular}

K, Kenya; T, total; “+," produce of wheat genotype sampled; “-," produce of wheat genotype not sampled; CT, certified commercial wheat seeds; FS, farm-saved wheat "seeds."

were incidentally observable on some farms and some wheat grains. All (100\%) farmers whose wheat seeds were used in this study cited stem rust as the major fungal disease affecting sustainable wheat production.
3.2. Fusarium spp. Complex in Genotypes of Wheat Seeds at Harvest Time. Based on the identification key the authors of [33], 80 fungal isolates belonging to the genus Fusarium were identified. Distinctive morphological features of mycelia, pigment formation and conidial cells' formation were used to determine both similarities and differences among the isolates of Fusarium spp. Results following PCR amplification of DNA for each positive isolate exhibited single clear amplified band, with fragment total size of between $700 \mathrm{bp}$ and $710 \mathrm{bp}$ (Figure 3). Analysis and comparison of the resultant sequences with sequences from National Centre for Biotechnology Informatics (NCBI) database using Basic Alignment Search Tool for Nucleotide Sequences (BLASTN), https:// blast.ncbi.nlm.nih.gov/Blast.cgito, established species identities of the fungal isolates as Fusarium poae, F. tricinctum, F. heterosporum, F. culmorum, F. equiseti, Fusarium sp., $F$. verticillioides and $F$. oxysporum. Mean prevalence of Fusarium spp. among the three counties was not significantly (all $p>0.05$ ) different (Figure 4). However, exceptions in prevalence were observed at the species level with respect to $F$. verticillioides, F. oxysporum, F. tricinctum, F. culmorum, and Fusarium sp. among the 3 regions after LSD pairwise comparisons. These exceptions were observed in the occurrence of the following species: F. verticillioides between Nakuru and Uasin Gishu ( $p=0.591), F$. culmorum between Nakuru and Uasin Gishu $(p=1.00)$, F. tricinctum between Nakuru and Narok $(p=1.00)$, and Fusarium sp. between Narok and Uasin Gishu ( $p=0.078)$. Diversity indices for Fusarium spp. in the three regions were as follows: Nakuru County, 2.008; Narok, 1.4603; and Uasin Gishu, 1.2337. Based on descriptive statistics, wheat produce of certified seeds had a minimum of 0 amounts of Fusarium spp., while the maximum was 16 with a mean of 3.42. Wheat produce of farm-saved seeds had a minimum of 0 amounts of Fusarium spp. isolates while the maximum amount was 22 with a mean of 6.31 . The overall 


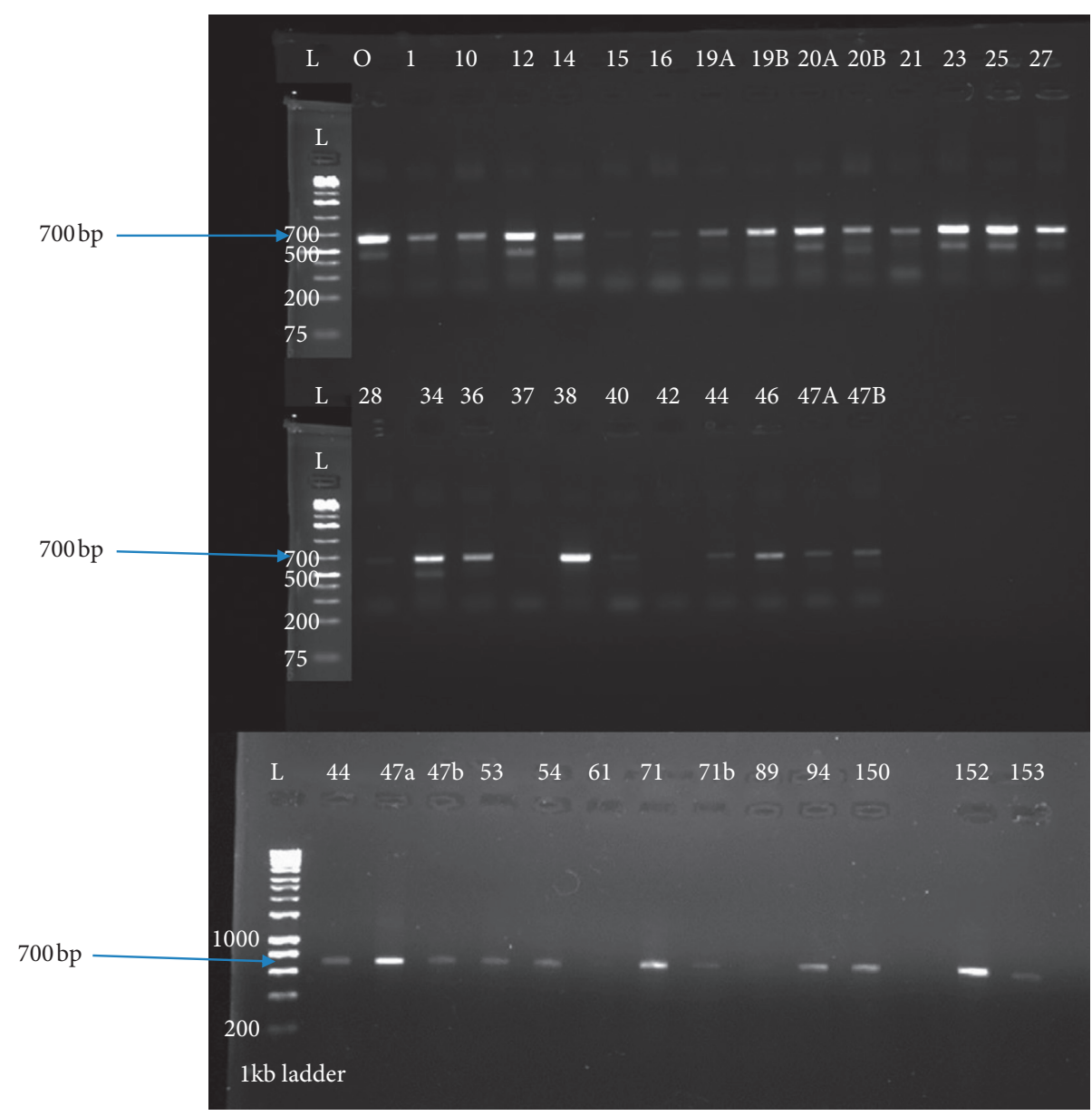

Figure 3: Agarose 1\% gel electrophoresis of PCR-amplified elongation factor 1-alpha gene of Fusarium spp. isolated from different genotypes of wheat seeds in three Rift Valley regions, Kenya. Amplification band of 700-710 bp shows positive results for identity of Fusarium spp.

amounts of Fusarium spp. per wheat variety in the category of farm-saved seeds were widely spread $(S D=6.626)$ and hence implicative of a higher prevalence of Fusarium spp. compared to those resulting from varieties of certified commercial wheat seeds (Table 2).

3.2.1. Phylogenetic Analysis of the Fusarium spp. Isolates. A phylogenetic tree generated to infer relatedness of the aligned sequences was constructed based on bootstrap values of over $75 \%$, while the identity of the isolates was based on identity matrix values lying between $95 \%$ and $100 \%$ in similarity with reference sequences in the NCBI. This analysis further confirmed the identity of the species and phylogenetic relations, revealing interspecies variation and intraspecies variation among members of $F$. verticillioides and $F$. equiseti, while some other fungal isolates emerged as outgroups. The phylogenetic tree divided the strains into four major clusters, namely, I, II, III, and IV (Figure 2). Fusarium strains identified under cluster I included F. verticillioides strain CNRG455, GeneBank accession (cc) no. MH936002; Fusarium sp. strain MCR2228, GeneBank accession no. MH582332; and F. verticillioides strain F28,
GeneBank accession no. KU554687. Identity matrix values for the strains ranged between $97.85 \%$ and $100 \%$ and were all supported by the bootstrap value of $100 \%$. Group II comprised of five Fusarium spp. (F. verticillioides strain CMCNRG455, GeneBank accession no. MH936002; F. tricinctum strain PPRI20693, GeneBank accession no. MH464151; F. heterosporum, GeneBank accession no. DAOMC235644; F. culmorum strain E24, GeneBank accession No. LT548347; Fusarium sp. isolate NRRL 20722, GeneBank accession no. GQ505595; and F. equiseti strain URM: 6788, GeneBank accession no. LS398491). The highest identity matrix value in this cluster was $99.85 \%$, supported by bootstrap values of $100 \%$ for all the species. Four (4) Fusarium spp. isolates (PT20, PT21, PT53, and PT7) in this cluster had low identity matrix and hence were treated as outgroups to node I and node II. Group III was supported by a bootstrap value of $100 \%$ and constituted of subclusters that divided the members into 3 Fusarium species: F. poae strain Montana II, MK729605; F. oxysporum, KU671036; and F. equiset $i$ isolate LQ144, MK168567 with similarity matrices of $97.67 \%, 89.15 \%$, and $100 \%$, respectively. In this cluster, Fusarium spp. isolate PT42 and PT51 emerged as out groups under the identity of F. equiseti isolate LQ144, MK168567. 


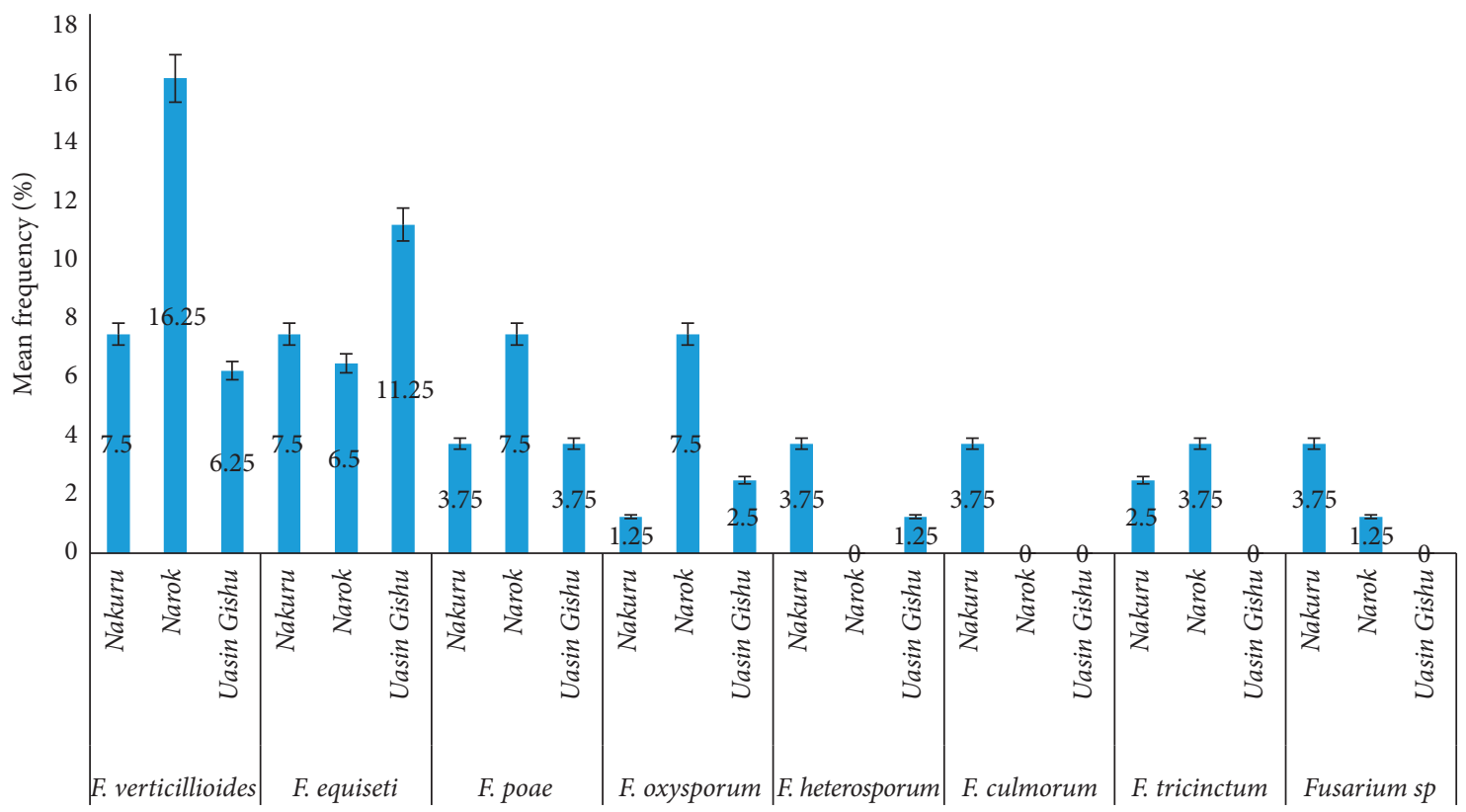

Figure 4: Means on prevalence of pathogenic Fusarium spp. in genotypes of wheat seeds at harvest time in three Rift Valley regions, Kenya.

Group IV Fusarium spp. strains had a bootstrap value of $100 \%$ and comprised of one-subcluster and one outgroup, PT61, whose reference accession identity was F. equiseti. This isolate was so prevalent in Uasin Gishu region. The subcluster was further divided into two groups, both of which had bootstrap values of $100 \%$. One of the groups comprised of $F$. equiseti isolate SAT73, with identity reference GeneBank accession no. DQ465946, while the other group consisted of $F$. verticillioides strain MRC929, GeneBank accession no. MH582324.

\subsubsection{Diversity of Pathogenic Fusarium spp. in the Wheat} Seed Varieties. The phylogenetic analysis shown in Figure 2 shows that $F$. verticillioides, F. equiseti, Fusarium poae, F. oxysporum, F. tricinctum, Fusarium sp., and F. culmorum comprised the pathogenic Fusarium spp. complex diversity prevalent in the sampled genotypes of wheat seeds (Table 3). Fusarium verticillioides and F. equiseti isolates were distributed across more than one cluster in the phylogenetic tree and were isolated from over $70 \%$ of all the wheat genotypes studied. Percentage prevalence of $F$. verticillioides, $F$. equiseti and $F$. poae in all the wheat seed genotypes was as follows: $94 \%, 77 \%$, and $50 \%$, respectively, compared to the prevalence of the other Fusarium spp. isolated. All the eight Fusarium spp. were more prevalent in Njoro II and Eagle 10 wheat seed genotypes, while Kenya Wren is the only wheat genotype that was not infected with Fusarium species (Table 3). Other than Robin wheat genotype, both Njoro II and Eagle 10 wheat genotypes were sampled from all the three regions of study in the following proportions: $44 \%, 15 \%$, and $9.5 \%$ for Njoro II, Eagle 10, and Robin, respectively. All of them were infected with over $50 \%$ of the isolated Fusarium species. Fusarium graminearum was not isolated from any of the wheat samples.

\section{Discussion}

The findings of this study suggest that freshly harvested wheat produce of both farm-saved and commercially processed wheat seeds was significantly infected with pathogenic Fusarium spp. that may inherently affect plant growth from germination. When such Fusarium spp. infected grains are used as seed for the next crop without decontamination, poor stands, poor vigor, and/or seedling blights can occur, substantially reducing optimal production of the crop. Fusarium spp. infected grains may as well be contaminated with mycotoxins that affect both human beings and domesticated animals that consume wheat products and wheat remains in the form of fodder, respectively. Farm-saved wheat seeds had a higher prevalence of Fusarium spp. compared to certified commercial wheat seeds despite the fact that they formed only $22.7 \%$ of the wheat grains sampled. Fusarium spp. infected grains in wheat debris also form an initial point for FHB contamination on farms and may contribute to propagation of FHB in the next crop especially in case of poor preharvest and postharvest wheat cultivation practices. Therefore, farmers should consistently use good quality, certified and decontaminated seeds to avoid initial fungal contamination by infected seeds $[37,38]$ and the subsequent disease effects [39]. Decontamination of seeds has been reported to increase grain yield and reduce amount of deoxynivalenol (DON) in wheat [40].

Ninety-four percent $(94 \%)$ of the wheat seed genotypes studied were infected with Fusarium spp., the major causative agents of FHB. This high prevalence indicates the susceptibility of some of the developed wheat genotypes to the disease. However, the prevalence and distribution of the fungal pathogens within the eighteen wheat genotypes sampled varied. Njoro II, Kenya Eagle 10, and Robin wheat genotypes were dominant in all the three regions, and they 
TABle 3: Pathogenic Fusarium spp. diversity in genotypes of wheat seeds in three Rift Valley regions, Kenya.

\begin{tabular}{|c|c|c|c|c|c|c|c|c|c|c|c|c|c|c|c|c|c|c|c|c|}
\hline \multirow{2}{*}{ Fusarium species } & \multicolumn{20}{|c|}{ Wheat genotypes and the occurrence of Fusarium spp. } \\
\hline & A & $\mathrm{B}$ & $\mathrm{C}$ & $\mathrm{D}$ & $\mathrm{E}$ & $\mathrm{F}$ & G & $\mathrm{H}$ & I & $\mathrm{J}$ & $\mathrm{K}$ & $\mathrm{L}$ & M & $\mathrm{N}$ & $\mathrm{O}$ & $\mathrm{P}$ & Q & $\mathrm{R}$ & S & $\mathrm{T}$ \\
\hline 1. F. verticillioides & $\checkmark$ & $\checkmark$ & $\checkmark$ & $\checkmark$ & $\sqrt{ }$ & $\checkmark$ & $\checkmark$ & $\checkmark$ & $\checkmark$ & $\checkmark$ & $\checkmark$ & $\checkmark$ & $\checkmark$ & $\checkmark$ & $\checkmark$ & $\checkmark$ & $\checkmark$ & $\checkmark$ & - & 18 \\
\hline 2. F. equiseti & $\checkmark$ & $\checkmark$ & $\checkmark$ & $\checkmark$ & - & $\checkmark$ & $\checkmark$ & $\checkmark$ & $\checkmark$ & $\checkmark$ & $\checkmark$ & $\checkmark$ & $\checkmark$ & $\checkmark$ & - & $\checkmark$ & $\checkmark$ & 一 & 一 & 15 \\
\hline 3. F. poae & $\checkmark$ & $\checkmark$ & - & $\checkmark$ & $\checkmark$ & - & $\checkmark$ & $\checkmark$ & - & - & $\checkmark$ & - & - & - & $\checkmark$ & - & $\checkmark$ & - & - & 9 \\
\hline 4. F. oxysporum & $\checkmark$ & $\checkmark$ & $\checkmark$ & $\checkmark$ & $\checkmark$ & $\checkmark$ & - & $\checkmark$ & - & - & - & - & - & $\checkmark$ & - & - & - & - & - & 8 \\
\hline 5. F. tricinctum & $\checkmark$ & $\checkmark$ & - & - & - & 一 & $\checkmark$ & $\checkmark$ & - & - & $\checkmark$ & - & - & $\checkmark$ & - & $\checkmark$ & 一 & 一 & 一 & 7 \\
\hline 6. F. heterosporum & $\checkmark$ & $\checkmark$ & - & - & - & - & $\checkmark$ & - & - & - & - & $\checkmark$ & - & - & - & - & - & - & - & 4 \\
\hline 7. Fusarium sp. & $\checkmark$ & $\checkmark$ & - & - & - & $\checkmark$ & - & - & $\checkmark$ & - & - & - & - & 一 & - & - & 一 & - & - & 4 \\
\hline 8. F. culmorum & $\checkmark$ & $\checkmark$ & - & - & $\checkmark$ & - & - & - & & - & - & - & - & - & - & - & - & - & - & 3 \\
\hline No. of $F$. species & 8 & 8 & 4 & 4 & 4 & 4 & 5 & 4 & 3 & 2 & 4 & 3 & 2 & 4 & 2 & 3 & 2 & 1 & 0 & \\
\hline
\end{tabular}

A, Njoro II; B, Eagle 10; C, unidentified wheat genotype; D, Robin; E, Kenya Ibis; F, Hawk; G, Duma; H, Ruiru; I, Kenya Korongo; J, Kwale; K, Kingbird; L, Simba; M, Ngamia; N, Mwamba; O, Fahari; P, Yombi; Q, Kenya Tai; R, Sunbird; S, Kenya Wren; T, total number of affected wheat varieties; “ $\checkmark$," isolated; “-," not isolated.

were all infected with over $50 \%$ of the isolated pathogenic fungi. Worth noting is the finding that all wheat genotypes (Kenya Tai, Kenya Sunbird, Kenya Wren, and Kenya Kingbird) developed for resistance against fungal diseases such as stem rust and yellow rust had less than $50 \%$ or had zero overall occurrence of Fusarium spp. However, Eagle 10 wheat genotype was an exception in this respect. Njoro II, farmers' most preferred wheat genotype, recorded the highest (25\%) rate of Fusarium sp. infestation in the category of farm-saved seeds compared to $3.75 \%$ that occurred in certified commercial genotypes (Eagle 10 and Kwale) of wheat seeds. The occurrence of F. culmorum, F. poae, $F$. equiseti, F. tricinctum, Fusarium sp., and F. verticillioides in almost all the wheat genotypes studied confirms the problem of pathogenic Fusarium spp. in the wheat crop in the regions. Fusarium oxysporum and F. heterosporum are among the less frequently or sporadically isolated Fusarium spp. in cereals such as maize [41] and hence, their occurrence in the studied wheat genotypes should be a concern for further research. Of significance was the absence of F. graminearum, the main causative agent of FHB in the isolated populations of Fusarium spp. isolates. This finding contradicts with existing research findings on occurrence of Fusarium spp. on wheat kernels in both Narok and Nakuru counties, in which F. graminearum has been previously reported $[26,27]$. The absence of $F$. graminearum might be due to the prolonged drought that existed in years 2016 and 2017 [42] when the crop was in season and did not favor the growth of the species. It may also be due to the decline in the population of this strain in the areas studied. The high prevalence of F. verticillioides, one of the causative agents of pink ear rot, in all the three regions of the study is in agreement with the existing reports on the wide distribution of the species $[32,33]$ and the report that it is the most common species isolated worldwide from diseased maize [43]. Its high prevalence in wheat is alarming, since it is a globally important pathogen of agriculture and livestock [44] and harmful fumonisins. The occurrence of Fusarium spp. in Uasin Gishu is significant due to scanty or lack of similar published data in the region compared to Narok and Nakuru counties.

The prevalence and diversity of the Fusarium spp. in the three regions was similar despite the fact that the regions are located in fairly different agro-ecological zones. This could be partly explained by the similarity in unfavorable changing climatic conditions, agronomy-related factors and farm practices in wheat production. The factors included cultivation of succeeding crops such as maize, barley and wheat, sharing of wheat farm tillage and harvesting equipment without strict observation of disease preventive measures, poor management of weeds, less fertilization, continuous land use, unskilled manpower and use of unprocessed low quality farmers' saved wheat seeds. Similar role of agro-economic factors in occurrences and propagation of FHB pathogens in wheat has been reported [45-48]. Infected wheat, barley, and maize debris usually act as the initial FHB inoculum $[46,49]$ on wheat farms. Consequently, consistent cultivation of these succeeding crops without proper farm management predisposes the wheat crop to the pathogens. Nakuru region recorded all the isolated Fusarium spp. which might be explained by two main reasons. First, there are many potentially susceptible wheat varieties cultivated in the area for research purposes. Second, the relatively warm and wet humid climatic conditions that characterize the region are favorable to FHB infestation.

Njoro II was the farmers' most preferred wheat variety because of its potential to produce high yields and to resist wheat rust. Only $1.63 \%$ of the farmers whose wheat seeds were sampled had knowledge about other fungal diseases such as FHB, while the majority had no idea. Over $90 \%$ of farmers recognized all fungal wheat diseases as "Wheat Rust" even where symptoms were for a different fungal infection. In Uasin Gishu, the farmers' minimal adoption of new wheat seed varieties was evident. Only four wheat genotypes (Njoro II, Robin, Simba, and Eagle 10) were cultivated. Existing reports suggest that limited knowledge on wheat seed management and adoption of new seed varieties [50], technical inefficiencies such as lack of farm equipment, lack of capital for farm inputs and application of less than recommended levels of fertilizers and use of low quality farm-saved seeds [22] hinder maximum potential of wheat farms. Therefore, awareness creation and education of farmers on the control of fungal wheat diseases and the related effects of mycotoxins in wheat production remains critical.

\section{Conclusion and Recommendations}

In conclusion, Fusarium spp. associated with mycotoxins that contaminate the wheat food chain seem to be rampant 
in the genotypes of wheat studied with no significant difference in both prevalence and diversity in the three regions of study. However, the variation in percentages of Fusarium spp. isolated from each wheat genotype provides evidence that some of the developed wheat genotypes might be more susceptible to pathogenic Fusarium species complex. The findings from this study also emphasize the impact of unprocessed and low quality farm-saved wheat grains in production of the wheat crop and its products. Wheat farmers are much more informed about wheat rust as compared to FHB. There is therefore a need for consolidative effort by stakeholders in wheat production to create awareness and educate farmers on control and management of all fungal diseases for sustainable wheat crop production. There is a need for increased extension services to farmers with the aim of inclusion in controlling FHB infestation in wheat crop and awareness on its effects from both economic and health perspective. Since only $10 \%$ of wheat genotypes developed for various purposes in Kenya is in use, there is a need for constant feedback from farmers on the criteria for selection of wheat genotypes. This information is helpful to wheat seed-producing companies in improving the resistance potential of existing varieties and/or development of new wheat genotypes with stronger resistance.

\section{Data Availability}

The data used to support the research findings of this study are available from the corresponding author upon request.

\section{Conflicts of Interest}

The authors declare that there are no conflicts of interest.

\section{Authors' Contributions}

OPK, OS, and WVW conceptualized and designed the study. OPK carried out field data collection. ISS and MO assisted OPK with sample collection and data analysis. OPK and ISS drafted the manuscript. OS, ISS, and WVV critically reviewed the manuscript. All authors read and approved the manuscript for publication.

\section{Acknowledgments}

The authors appreciate Mr. Wakoli, Mrs. Owiti Anne, and Kevin Ochwedo who assisted with technical work. They are indebted to Kenya Agricultural and Livestock Research Organization, Kabete, for facilitating this work by providing working space. The research work was funded by the government of Kenya National Commission for Science, Technology and Innovation (NACOSTI) under research grant number (NACOSTI/RCD/ST\&7TH CALL/PHD/215).

\section{References}

[1] A. Logrieco, A. Moretti, G. Perrone, and G. Mulè, "Biodiversity of complexes of mycotoxigenic fungal species associated with Fusarium ear rot of maize and Aspergillus rot of grape," International Journal of Food Microbiology, vol. 119, no. 1-2, pp. 11-16, 2007.

[2] L. Gong, Y. Jiang, and F. Chen, "Molecular strategies for detection and quantification of mycotoxin-producing Fusarium species: a review," Journal of the Science of Food and Agriculture, vol. 95, no. 9, pp. 1767-1776, 2015.

[3] P. Giraldo, E. Benavente, F. Manzano-Agugliaro, and E. Gimenez, "Worldwide research trends on wheat and barley: a bibliometric comparative analysis," Agronomy, vol. 9, no. 7, p. 352, 2019.

[4] P. R. Shewry and S. J. Hey, "The contribution of wheat to human diet and health," Food and Energy Security, vol. 4, no. 3, pp. 178-202, 2015.

[5] A. Bernhoft, M. Torp, P.-E. Clasen, A.-K. Løes, and A. B. Kristoffersen, "Influence of agronomic and climatic factors onFusariuminfestation and mycotoxin contamination of cereals in Norway," Food Additives \& Contaminants: Part A, vol. 29, no. 7, pp. 1129-1140, 2012.

[6] C. C. Dweba, S. Figlan, H. A. Shimelis et al., "Fusarium head blight of wheat: pathogenesis and control strategies," Crop Protection, vol. 91, pp. 114-122, 2017.

[7] V. Scala, G. Aureli, G. Cesarano et al., "Climate, soil management, and cultivar affect Fusarium head blight incidence and deoxynivalenol accumulation in durum wheat of Southern Italy," Frontiers in Microbiology, vol. 7, no. JUN, pp. 1-10, 2016.

[8] A. Wenda-Piesik, G. Lemańczyk, M. Twarużek, A. BłajetKosicka, M. Kazek, and J. Grajewski, "Fusarium head blight incidence and detection of Fusarium toxins in wheat in relation to agronomic factors," European Journal of Plant Pathology, vol. 149, no. 3, pp. 515-531, 2017.

[9] M. Mcmullen, S. Halley, B. Schatz, S. Meyer, J. Jordahl, and J. Ransom, "Integrated strategies for fusarium head blight management in the United States," Cereal Research Communications, vol. 36, no. Supplement 6, pp. 563-568, 2008.

[10] S. N. Wegulo, P. S. Baenziger, J. Hernandez Nopsa, W. W. Bockus, and H. Hallen-Adams, "Management of Fusarium head blight of wheat and barley," Crop Protection, vol. 73, pp. 100-107, 2015.

[11] É. Bonfada, D. Honnef, M. T. Friedrich, W. Boller, and C. C. Deuner, "Performance of fungicides on the control of fusarium head blight (Triticum aestivum L.) and deoxynivalenol contamination in wheat grains," Summa Phytopathologica, vol. 45, no. 4, pp. 374-380, 2019.

[12] D. L. D. Angelo, P. Pathology, and T. Ohio, “D’Angelo 2014 FHB DON fungicide timing post-anthesis prosaro metconazole," Journal of Plant Diseases, vol. 60, no. 10, pp. 13871397, 2014.

[13] M. Haidukowski, M. Pascale, G. Perrone, D. Pancaldi, C. Campagna, and A. Visconti, "Effect of fungicides on the development of Fusarium head blight, yield and deoxynivalenol accumulation in wheat inoculated under field conditions with Fusarium graminearum and Fusarium culmorum," Journal of Plant Pathology, vol. 85, pp. 191-198.

[14] M. Yoshida, T. Nakajima, K. Tomimura, F. Suzuki, M. Arai, and A. Miyasaka, "Effect of the timing of fungicide application on Fusarium head blight and mycotoxin contamination in wheat," Plant Disease, vol. 96, no. 6, pp. 845-851, 2012.

[15] M. Beyer, M. B. Klix, H. Klink, and J.-A. Verreet, "Quantifying the effects of previous crop, tillage, cultivar and triazole fungicides on the deoxynivalenol content of wheat grain - a review," Journal of Plant Diseases and Protection, vol. 113, no. 6, pp. 241-246, 2006. 
[16] M. Blandino, M. Haidukowski, M. Pascale, L. Plizzari, D. Scudellari, and A. Reyneri, "Integrated strategies for the control of Fusarium head blight and deoxynivalenol contamination in winter wheat," Field Crops Research, vol. 133, pp. 139-149, 2012.

[17] M. Blandino, V. Scarpino, M. Sulyok, R. Krska, and A. Reyneri, "Effect of agronomic programmes with different susceptibility to deoxynivalenol risk on emerging contamination in winter wheat," European Journal of Agronomy, vol. 85, pp. 12-24, 2017.

[18] L. Shah, A. Ali, M. Yahya et al., "Integrated control of fusarium head blight and deoxynivalenol mycotoxin in wheat," Plant Pathology, vol. 67, no. 3, pp. 532-548, 2018.

[19] T. Nakajima, M. Yoshida, and K. Tomimura, "Effect of lodging on the level of mycotoxins in wheat, barley, and rice infected with the Fusarium graminearum species complex," Journal of General Plant Pathology, vol. 74, no. 4, pp. 289-295, 2008.

[20] E. M. Janssen, M. C. M. Mourits, H. J. van der Fels-Klerx, and A. G. J. M. O. Lansink, "Pre-harvest measures against Fusarium spp. infection and related mycotoxins implemented by Dutch wheat farmers," Crop Protection, vol. 122, pp. 9-18, 2019.

[21] J. Kamwaga, G. Macharia, L. Boyd et al., "Kenya wheat production handbook 2016," Experimental Agriculture, vol. 37, no. 1, 2016.

[22] S. Mburu, C. Ackello-Ogutu, and R. Mulwa, "Analysis of economic efficiency and farm size: a case study of wheat farmers in Nakuru district, Kenya," Economics Research International, vol. 2014, Article ID 802706, 10 pages, 2014.

[23] S. Alessandro, J. Caballero, J. Lichte, and S. Simpkin, "Kenyan agricultural sector risk assessment,” p. 126, 2015 Agricultural Global Practice Technical Assistance Paper, World Bank Group, Washington, DC, USA, 96289.

[24] N. T. Beatrice, P. O. Pascal, O. Daniel, and O. Maurice, "Wheat stem rust disease incidence and severity associated with farming practices in the Central Rift Valley of Kenya," African Journal of Agricultural Research, vol. 11, no. 29, pp. 2640-2649, 2016.

[25] J. W. Muthomi, S. L. Musyimi, J. M. Wagacha, and R. D. Narla, "Occurrence of Fusarium species and associated T2-toxin in Kenyan wheat," Journal of Agricultural Sciences, vol. 3, no. 1, pp. 24-34, 2012.

[26] J. W. Muthomi, J. K. Ndung'u, J. K. Gathumbi, E. W. Mutitu, and J. M. Wagacha, "The occurrence of Fusarium species and mycotoxins in Kenyan wheat," Crop Protection, vol. 27, no. 8, pp. 1215-1219, 2008.

[27] J. M. Wagacha, N. K. Njeru, O. O. Okumu, J. W. Muthomi, and C. K. Mutegi, "Occurrence of Fusarium head blight of wheat and associated mycotoxins in Narok and Nakuru Counties, Kenya," World Journal of Agricultural Research, vol. 4, no. 4, pp. 119-127, 2016.

[28] H. El-Shall and B. M. Moudgil, "Design of optimum sampling plans for dry powders and slurries," KONA Powder and Particle Journal, vol. 31, no. 1, pp. 82-91, 2014.

[29] L. Freese, J.-W. Chen, and R. D. Shillito, "Sampling of grain and seed to estimate the adventitious presence of biotechnology-derived seeds in a lot," Cereal Foods World, vol. 60, no. 1, pp. 9-15, 2015.

[30] P. E. Nelson, A. E. Desjardins, and R. D. Plattner, "Fumonisins, mycotoxins produced by fusarium species: biology, chemistry, and significance," Annual Review of Phytopathology, vol. 31, no. 1, p. 233, 1993.
[31] H. I. Nirenberg, "A simplified method for identifying Fusarium spp. occurring on wheat," Canadian Journal of Botany, vol. 59, no. 9, pp. 1599-1609, 1981.

[32] L. W. Burgess, Laboratory Manual for fusarium Research, Fusarium Research Laboratory, Dept. of Crop Sciences, University of Sydney: Royal Botanic Gardens, Sydney, Australia, 3rd edition, 1994.

[33] J. F. Leslie and B. A. Summerrell, The fusarium Laboratory Manual, Blackwell Pub, Hoboken, NJ, USA, 1st ed. edition, 2006.

[34] D. M. Geiser, M. del Mar Jiménez-Gasco, S. Kang et al., "FUSARIUM-ID v. 1.0: a DNA sequence database for identifying Fusarium," European Journal of Plant Pathology, vol. 110, no. 5/6, pp. 473-479, 2004.

[35] S. Kumar, G. Stecher, M. Li, C. Knyaz, and K. Tamura, "Mega $\mathrm{X}$ : molecular evolutionary genetics analysis across computing platforms," Molecular Biology and Evolution, vol. 35, no. 6, pp. 1547-1549, 2018.

[36] K. Tamura, G. Stecher, D. Peterson, A. Filipski, and S. Kumar, "MEGA6: molecular evolutionary genetics analysis version 6.0," Molecular Biology and Evolution, vol. 30, no. 12, pp. 2725-2729, 2013.

[37] S. A. Inch and J. Gilbert, "Survival of Gibberella zeae in Fusarium-damaged wheat kernels," Plant Disease, vol. 87, no. 3, pp. 282-287, 2003.

[38] W. E. May, M. R. Fernandez, and G. P. Lafond, "Effect of fungicidal seed treatments on the emergence, development, and grain yield of Fusarium graminearum-infected wheat and barley seed under field conditions," Canadian Journal of Plant Science, vol. 90, no. 6, pp. 893-904, 2010.

[39] W. E. Nganje, S. Kaitibie, W. W. Wilson, L. F. Leistritz, and D. A. Bangsund, "Economic impacts of fusarium head blight in wheat and barley: 1993-2001," Agribusiness \& Applied Economics, no. 538, pp. 1-62, 2004.

[40] A. G. Xue, W. Guo, Y. Chen et al., "Effect of seed treatment with novel strains of Trichoderma spp. on establishment and yield of spring wheat," Crop Protection, vol. 96, pp. 97-102, 2017.

[41] A. Bottalico, "Fusarium diseases of cereals : species complex and related mycotoxin profiles," Journal of Plant Pathology, vol. 80, no. 2, pp. 85-103, 1998.

[42] W. Schmidt, A. Peter Uhe, J. Kimutai, F. Otto, and H. Cullen, The drought in Kenya, 2016-2017. Climate and development knowledge Network and world weather attribution initiative, paper April, 1-8, 2017.

[43] G. P. Munkvold and A. E. Desjardins, "Fumonisins in maize: can we reduce their occurrence?" Plant Disease, vol. 81, no. 6, pp. 556-565, 1997.

[44] D. Nagaraj and M. Sreenivas, "Fusarium verticillioides, a globally important pathogen of agriculture and livestock: a review," Journal of Veterinary Medicine and Research, vol. 4, no. 4, p. 1084, 2017.

[45] X. Guo, D. Fernando, P. Bullock, and H. Sapirstein, "Quantifying cropping practices in relation to inoculum levels of fusarium graminearum on crop stubble," Plant Pathology, vol. 59, no. 6, pp. 1107-1113, 2010.

[46] M. D. Keller, A. B. Baudoin, W. E. Thomason, and B. A. Vinatzer, The contribution of within-field inoculum sources of gibberella zeae to fusarium head blight in winter wheat and barley, PhD Thesis, Virginia Polytechnic Institute, Blacksburg, VA, USA, 2011.

[47] N. Njeru, M. Wagacha, J. W. Muthomi, and C. Mutegi, "Role of soil and crop residues as sources of inoculum for Fusarium head blight of wheat," in Proceedings of the Fourth RUFORUM 
Biennial Regional Conference, Maputo, Mozambique, pp. 213-217.

[48] N. K. Njeru, J. W. Muthomi, C. K. Mutegi, and J. M. Wagacha, "Effect of cropping systems on accumulation of fusarium head blight of wheat inocula in crop residues and soils," Journal of Plant Sciences, vol. 11, no. 1, pp. 12-21, 2016.

[49] J. M. Wagacha, U. Steiner, H.-W. Dehne et al., "Diversity in mycotoxins and fungal species infecting wheat in Nakuru district, Kenya," Journal of Phytopathology, vol. 158, no. 7-8, pp. 527-535, 2010.

[50] P. Gamba and C. Ngugi, "Wheat farmers' seed management and varietal adoption in Kenya," Journal of Plant Breeding, pp. 53-62, 2003. 